\title{
LAS NUEVAS FUENTES PARA EL ESTUDIO DE LA FILOSOFÍA DEL DERECHO HEGELIANA *
}

\section{Introducción}

egel dedicó especial atención a aquella parte de su sistema filosófico que se
ocupa del «espíritu objetivo». Sobre este tema, no sólo publicó una obra
específica, las Grundlinien der Philosophie des Rechts de 1820 , sino que le
dedicó, además, siete cursos de lecciones entre los años 1817 y 1831 .
Las significativas discrepancias existentes entre el texto publicado por Hegel y los Vorlesungsnachschriften -cuadernos de apuntes tomados por los oyentes durante las clases- llevaron a Karl-Heinz Ilting a publicar, en 1973-74, todo el material del que se disponía en el momento'.

* Quiero agradecer a mi amiga la profesora Pilar Giménez Alcover la traducción de este artículo.

${ }^{1}$ Cfr. G. W. F. Hegel, Vorlesungen über Rechisphilosophie 1818-31, Edition und Kommentar in 6 Bde, von K.-H. Ilting, Frommann-Holzboog, Stuttgart-Bad Canstatt Bd. I., 1973; Bde. II.-III.-IV, 1974.

Bd. I: Der objektive Geist, aus der Heidelberger Enzyklopädie mit Hegels Vorlesungsnotizien 1818-19; Naturrecht uns Staatswissenschaft nach der Vorlesungsnachrift von C. G. Homeyer 1818-19; Zeitgenössische Rezensionen der «Rechtsphilosophie».

Bd. II: Die «Rechtsphilosophie» von 1820, mit Hegels-Vorlesungsnotizien 1821-25.

Bd. III: Philosophie des Rechts nach der Vorlesungsnachschrift H. G. Hotho 1822-23.

Bd. IV: Philosophie des Rechts nach der Vorlesungsnachschrift K. G. von Griesheims 1824-25; Der objektive Geist, aus der Berliner Enzyklopädie zweite und dritte Auflage (1827 und 1830); Philosophie des Rechis nach der Vorlesungsnachschrift von D. F. Strauß 1831, mit Hegels Vorlesungsnotizien.

La edición está acompañada de una amplia introducción y de prefacios concretos a cada Vorlesung. Gran parte de estos trabajos han aparecido también en traducción italiana: Karl-Heinz Ilting, Hegel diverso, Le filosofie del diritto dal 1818 al 1831, a cura di E. Tota, Roma-Bari, Laterza, 1977. Existe una traducción reciente al castellano del curso de lecciones de 1918-19; G. W. 
Diez años después, la publicación de dos nuevos cursos de lecciones nos permite obtener un cuadro casi general de la formación y desarrollo de la obra hegeliana y ampliar ulteriormente el conocimiento de su pensamiento filosófico-jurídico. El mérito de estas nuevas iniciativas editoriales corresponde a Dieter Henrich, que ha cuidado la publicación del curso 1819-20² y, de nuevo, Karl-Heinz Ilting, editor del primer curso desarrollado por Hegel en Heidelberg en 1817-18 ${ }^{3}$. De este curso existe otra edición a cargo de la Hegel-Archiv de Bochum ${ }^{4}$.

En las páginas siguientes se intentará proporcionar al lector la información más exhaustiva posible sobre la nueva situación de las fuentes para la interpretación del pensamiento filosófico jurídico de Hegel, así como alguna aclaración sobre su proceso de formación.

F. Hegel, Lecciones sobre Filosofía del Derecho (1818-19), en traducción de Luisa H. de Meyer y con un prólogo de Karl-Heinz Ilting, Argentina, Editorial Universidad de Motón, 1983.

${ }^{2}$ Cfr. G. F. W. (sic!) Hegel, Philosophie des Rechts. Die Vorlesung von 1819-20 in einer Nachschrift, herausgegeben von D. Henrich, Frankfurt a. M., Suhrkamp, 1983. Acompaña al volumen una amplia introducción que analiza los elementos más cualificados de esta Vorlesungsnachschrift y desarrolla una interpretación en clave «institucionalista» de la Filosofía del Derecho. Le sigue una elaborada nota informativa, un complejo aparato de notas y comentarios y un breve apéndice que informa sobre la aparición de la Rph I. No falta tampoco una concordancia con Rph que, sin embargo, es poco útil por estar separada del texto y colocada como tabla al final del volumen.

${ }^{3}$ Cfr. G. W. F. Hegel, Die Philosophie des Rechts. Die Mitschriften Wannmann (Heidelberg 1817-18) und Homeyer (Berlin 1818-19), herausgegeben von K.-H. Ilting, Stuttgart, Klett-Cotta, 1983. Ilting publica no sólo el texto inédito del primer curso de lecciones, sino también una edición renovada del curso de lecciones transcritas por Homeyer. Esta edición merece especial atención por el extraordinario cuidado con que ha sido realizada. Ilting, que ha dedicado a esta lección un seminario altamente especializado durante tres semestres, no se ha limitado a aportar una notable introducción de la que emerge en todo su alcance un Hegel teórico del constitucionalismo, e inserto por derecho propio en el debate constitucional de la época, sino que proporciona, en un magnífico aparato de notas explicativas, un extraordinario comentario de los aspectos más significativos de las lecciones. El volumen está además acompañado de una elaborada nota editorial y de un utilísimo índice analítico que permite interesantes revelaciones. Junto a cada parágrafo se indica la concordancia no sólo con Rph, sino también con los otros cursos precedentes. Es, por tanto, una obra que une a la fiabilidad filológica una serie de instrumentos de consulta de gran utilidad.

${ }^{4}$ Cfr. G. W. F. Hegel Vorlesungen über Naturrecht und Staatswissenschaft (1817-18). Nachschrift P. Wannmann. Herausgegeben von D. Becker, W. Bonsiepen, A. Genthmann-Siefert, F. Hogermann, W. Jaeschke, Ch. Jamme, H.-Ch. Lucas, K. R. Meist, H. Schneider. Mit einer Einleitung von O. Pöggeler, Hamburg, Meiner, 1983. 


\section{El cuadro de las fuentes}

El primer esbozo de lo que será la Filosofía del Derecho se encuentra en la sección de la Enzyklopädie de Heidelberg (aparecida en junio de 1817) dedicada al «espíritu objetivo» (párrafos 400 a 452). En los tres años siguientes, antes de la publicación de las Grundlinien der Philosophie des Rechts, Hegel impartió durante los semestres de invierno clases de Filosofía del Derecho:

$\begin{array}{ll}\text { Rph I } & \text { Heidelberg 1817-18 } \\ \text { Rph II } & \text { Berlín 1818-19 } \\ \text { Rph III } & \text { Berlín 1819-20 }\end{array}$

De estos cursos sólo se conocía hasta hoy la Rph II, conservada en una copia de apuntes compilada por C. G. Homeyer y publicada por Ilting en 1973.

Como se ha indicado, la Rph I y la Rph III constituyen las novedades editoriales más recientes. Ello significa que, en el momento presente, podemos reconstruir de la forma más precisa posible la «Entstehungsgeschichte»-la historia de los orígenes- de la Filosofía del Derecho de Hegel, pues justo después, en octubre de 1820 (aun cuando conste en el frontispicio la fecha de 1821), aparecieron las Grundlinien der Philosophie des Rechts.

Puede decirse que la obra concluyó el 25 de junio de 1820, fecha en que acabó el prefacio. La impresión de la obra duró más de lo habitual a causa de la censura. En cualquier caso, el 10 de octubre de 1820 -como se desprende de la carta que le acompañaHegel ya pudo enviar una copia del libro apenas aparecido al ministro prusiano Altenstein (vid. Briefe, Bd. II, pág. 238). La confirmación directa de la aparición del volumen de Hegel durante la primera mitad de octubre se encuentra en una carta de agradecimiento de Hinrichs, por el libro recibido como regalo (14 de octubre de 1820, Briefe, Bd. II, pág. 238). También se halla una confirmación indirecta en una carta de von Thaden ( 8 de agosto de 1821, Briefe, Bd. II, pág. 278). Por otro lado, la obra se anunciaba entre las novedades editoriales (de la Nicolaische Buchhandlung de Berlín) para la Michaelis-Messe (Leipzig) de octubre de 1820. No parece constituir problema la fecha del frontispicio, pues según W. Olbrich (Einführung in die Verlagskunde, Stuttgart, 1955, pág. 131) el que obras publicadas el último trimestre del año aparecieran con la fecha del año posterior no era un hecho insólito. 
Este libro será también utilizado para las lecciones directamente sucesivas:

$\begin{array}{ll}\text { Rph IV } & \text { Berlín 1821-22 } \\ \text { Rph V } & \text { Berlín 1822-23 } \\ \text { Rph VI } & \text { Berlín 1824-25 }\end{array}$

Hasta ahora sólo han sido publicadas dos cuadernos de apuntes de los dos últimos años, cursos recopilados por H. G. Hotho (Rph V) y por K. G. von Griesheim (Rph VI), respectivamente y publicados por Ilting en 1974. Un manuscrito hasta ahora inédito que se refiere probablemente al semestre de invierno 1821-22 está en curso de publicación ${ }^{5}$.

Entre 1825 y 1830 Hegel no consideró oportuno impartir clases sobre esta parte de su sistema filosófico, dejando a sus discípulos Leopold von Henning, Karl Ludwig Michelet y, sobre todo, Eduard Gans la tarea de tratarla en sus lecciones.

En este período, el trabajo de Hegel en el campo de la Filosofía del Derecho se reduce a una nueva redacción de las secciones sobre el «espíritu objetivo» en las dos ediciones sucesivas de la Enzyklopädie (julio de 1827 y octubre de 1830).

Tan sólo en el semestre de invierno de 1831-32, tras haber anulado «por indisposición» un curso de Filosofía del Derecho anunciado para el semestre del 30-31 en el que fue sustituido por Michelet ${ }^{6}$, Hegel empezó el nuevo curso, pero tras sólo dos lecciones murió de improvisto. Se trata de:

\section{Rph VII Berlín 1831}

conservada en la copia de apuntes de D. F. Strauss, publicada también por Ilting.

Permítaseme hacer referencia a los motivos que indujeron a Hegel a retomar el curso de Filosofía del Derecho:

En primer lugar, debe recordarse el testimonio proporcionado por Arnold Ruge: «Estaba Hegel un día comiendo en casa del príncipe heredero -el futuro Federico Guillermo IV-. ?Es un escándalo -decía el anfitrión real- que el profesor Gans nos

${ }^{5}$ Sobre este manuscrito que constituye la última novedad en el campo de las Vorlesungen hegelianas me permito reenviar a mi nota informativa: «Hegelsche Vorlesungsnachschriften und noch kein Ende?» en Materiali per una storia della cultura giuridica, XVI, núm. 1, 1986, págs. 251-261.

${ }^{6}$ Cfr. G. W. F. Hegel, Berliner Schriften 1818-31, herausgegeben von J. Hoffmeister, Hamburg, Meiner, 1955, pág. 749. 
convierta a todos los estudiantes en republicanos. Sus lecciones sobre su Filosofía del Derecho, señor profesor, son frecuentadas por muchos centenares de estudiantes y es suficientemente conocido que da a sus tratamientos un tinte completamente liberal, incluso republicano. ¿Por qué no da las lecciones usted mismo?” Hegel no rebatió esta descripción, se excusó diciendo que no sabía lo que Gans explicaba en las lecciones y se comprometió a dar la Filosofía del Derecho él mismo el semestre siguiente» ${ }^{7}$.

Otra versión de los sucesos, a decir verdad algo más confusa, nos la proporciona J. E. Erdmann: «La acusación de que su (de Hegel) filosofía política era antiprusiana y revolucionaria se hizo más preocupante cuando Hegel notó que algunos de sus discípulos consideraban de manera muy distinta a la suya los sucesos de la época y cuando alguien, de quien no podía tomar la advertencia a la ligera, hizo notar al filósofo que aquel a quien había confiado las lecciones del curso sobre Derecho natural, es decir, Gans, obtenía de sus (de Hegel) principios consecuencias relativas a Bélgica y a Polonia que debían ser definidas, necesariamente, como revolucionarias. Ello llevó a Hegel a retomar él mismo las lecciones (de Filosofía del Derecho) que desde hacía tiempo no explicaba» ${ }^{8}$.

Tanto para Ruge como para Erdmann, la causa que llevó a Hegel a impartir de nuevo lecciones de Filosofía del Derecho en el semestre invernal de 1831-32 fue extrínseca y ha, de atribuirse más a una directiva superior (el príncipe heredero o una instancia oficial imprecisa) que a una libre decisión propia. Si bien puede plantearse alguna duda sobre esta interpretación si se tiene en cuenta que Hegel ya había anunciado un curso, luego anulado, para 1830 , lo que podría hacer suponer también la existencia de alguna divergencia real entre Hegel y Gans ${ }^{9}$.

Una cosa, sin embargo, no excluye a la otra. Ambas se explican por la difícil situación en la que se encontró Hegel el último año de su vida: preso entre su rol oficial de filósofo del estado

${ }^{7}$ Cfr. A. Ruge, Aus früherer Zeit, Bd. IV, Berlín, 1867, pág. 431. El documento puede consultarse en Hegel in Berichten seiner Zeitgenossen, herausgegeben von G. Nicolin, Hamburg, Meiner, 1970, págs. 437-438. Sobre A. Ruge vid mi colaboración «Notas sobre Arnold Ruge: la interpretación política de la ?Rechtsphilosophie" hegeliana», en Sistema, 49, 1982, págs. 129-140. y sigs.

${ }^{8}$ Cfr. la voz «Hegel», en Allgemeine Deutsche Biographie, Leipzig, 1880, Bd. XI, págs. 272

${ }^{9}$ Cfr. M. Riedel, «Eduard Gans als Schüler Hegels, Zur Politischen Auslegung der Rechtsphilosophie», en Rivista di Filosofia, fascículo especial Hegel e lo stato, octubre 1977, págs. 234-253 (237). El texto aparece también en versión italiana págs. 254-268. 
prusiano que lo ponía en contraste con sus mejores discípulos y las presiones ejercidas por estos últimos para que tomara posición abiertamente a favor de los objetivos políticos de la Revolución de julio.

El cuadro de las fuentes, para ser totalmente exhaustivo, ha de comprender también las vorlesungsnotizien (es decir, las anotaciones autógrafas de Hegel a las lecciones) de los $\S \S 400-452$ de la Enzyklopädie de Heidelberg, escritas en su mayoría entre febrero de 1818 y finales de marzo de 1819, así como las Vorlesungsnotizien de los años 1821-25 de las Grundlinien, publicadas ambas por Ilting en una edición, finalmente, satisfactoria.

Estas últimas son de particular interés para la comprensión del ulterior desarrollo del pensamiento iusfilosófico hegeliano después de la publicación de las Grundlinien.

G. Lasson (en Hegel-Archiv, Bd. II, Heft 2, 1914 y Bd. III, Heft 1-2, 1916) ya había publicado las anotaciones autógrafas de Hegel referentes a las lecciones del período 1821-25, pero lo hizo como si se tratara de un texto único y unitario, en definitiva, como si hubiera sido escrito en el mismo período. Dado que Hegel, por falta de espacio, había tenido que insertar apuntes en tiempos sucesivos junto a, o con, anotaciones precedentes, nació, de la edición de Lasson, un texto en ocasiones confuso, a veces incomprensible y, en cualquier caso, inutilizable. También Hoffmeister siguió el mismo criterio en su edición de las Grundlinien (Hamburgo, 1955), criterio que está en la base de numerosas ediciones alemanas e italianas (las anotaciones autógrafas de Hegel fueron traducidas por A. Plebe en la edición de la Filosofia del Diritto dirigida por F. Messineo, 1954, Bari, Laterza). A K.-H. Ilting debe de nuevo imputarse el mérito de haber atribuido estas notas a cada uno de los semestres y, por tanto, el de haberlas fechado, presentando, por vez primera, un texto realmente fiable.

Se ha querido proporcionar un panorama de las fuentes, lo más exhaustivo posible, porque creemos que de esta forma se puede dar cuenta del hecho que la Filosofía del Derecho, más aún que la Scienza Nuova de Vico ${ }^{10}$, es una obra que se presenta en una pluralidad de versiones. Ciertamente, la Filosofía del Derecho de 1820, si se excluyen las Vorlesungsnotizien, es la única elaboración escrita que proviene de Hegel, pero, dado que fue

${ }^{10}$ La sorprendente analogía entre los destinos de ambas obras fue subrayada por mí en el artículo «Origini della ?Wirkingsgeschichte" di Vico in Germania», en Materiali per una storia della cultura giuridica, XI, núm. 2, 1981, págs. 314-316. 
publicada en un momento en que la situación política era verdaderamente excepcional ${ }^{11}$, no puede ser considerada como el tratado más auténtico.

Podría mencionarse otro problema: el relativo al grado de credibilidad de las Vorlesungsnachschriften, pero creemos que esta cuestión ya ha sido extraordinariamente bien resuelta por Ilting, en su polémica con Hoffmeister y en sus críticas a Plebe ${ }^{12}$ y hoy, en el ámbito de la «Hegel-Forschurig», ya nadie pone en duda la fiabilidad de los apuntes de las lecciones.

Aparte del hecho de que, alguna de ellas (Rph I, Rph II) es, por lo menos en lo que se refiere a los parágrafos, la transcripción de un dictado hegeliano, algunas copias de apuntes de las lecciones berlinesas fueron utilizadas por el propio Hegel como base para sus lecciones. Esto lo sabemos por lo que escribió Marheineke en el prefacio a su edición de las Lecciones sobre la Filosofía de la Religión: «Los apuntes, que habían sido tomados durante las lecciones que (Hegel) dictó en 1824, fueron hechos transcribir para Hegel por uno de sus oyentes más próximos: el señor capitán von Griesheim. De este cuaderno se sirvió el propio Hegel en 1827 para consultarlo en la cátedra e incluso lo enriqueció con añadidos y correcciones propias que, la mayoría de las veces, no eran sino palabras sueltas y proposiciones a desarrollar ulteriormente durante la exposición oral. El cuaderno que se compiló durante las lecciones de Hegel, este mismo año 1827, y que, una vez transcrito, incluso se le regaló, fue redactado por uno de nuestros mejores auditores de la época: el señor Meyer, de nacionalidad suiza. En 1831, Hegel, con motivo de una reexposición de esta ciencia, lo usó en la cátedra añadiéndole igualmente nuevos esbozos para el desarrollo oral» ${ }^{13}$.

Frente a estas declaraciones, sorprende aún más que Hoffmeister haya podido dudar del grado de fiabilidad de las copias

${ }^{11} \mathrm{El}$ ambiente existente en el momento de la publicación ha sido ampliamente desvelado por K.-H. Ilting: Hegel diverso, op. cit., passim.

${ }^{12}$ Vid. págs. 135-154. Sobre las tesis de Hoffmeister véase su Prefacio a G. W. H. Hegel, Grundlinien der Philosophie des Rechts, Hamburgo, Meiner, 1955, Págs. VII-XVII. Hoffmeister critica muy enérgicamente, si bien con argumentos poco convincentes, tanto a los dos autores de las copias de apuntes (Hotho y von Griesheim) como a Gans en su calidad de redactor de los añadidos. Ya antes de Ilting, E. Moldenhauer y K. Michel, en su edición de las obras de Hegel publicada por Suhrkamp, 1969-75 (vol. VII, Grundlinien der Philosophie des Rechts, 1970, pág. 528), habían puesto de relieve que los ejemplos proporcionados por Hoffmeister eran «freilich wenig überzeugend».

${ }^{13} \mathrm{Cfr}$. el prefacio de Marheinecke a G. W. F. Hegel Sämtliche Werke, Jubiläunsausgabe in 20 Bde, herausgegeben von H. Glockner, Stuttgart, Frommart-Verlag, 1927-40 (Bd. XV, págs. 1 y sigs.). 
de apuntes. De hecho, parece incomprensible que el mismo Hegel se hubiera servido de aquellos apuntes como base para sus lecciones si efectivamente éstos hubiesen torcido o no reproducido fielmente su pensamiento.

Se podrá ciertamente discutir si la versión auténtica del pensamiento de un filósofo está constituida por las obras que éste dio a la imprenta o por sus cursos de lecciones, pero, una vez garantizada la autenticidad de las copias de apuntes de los que se dispone, creo que no puede negarse que, en determinadas circunstancias, éstos pueden adquirir una cierta «plusvalía» con respecto a los textos. $\mathrm{Y}$ esto es válido en particular para las obras de contenido ius-político, especialmente sujetas a condicionamientos históricos. Por ello, toda futura interpretación de la filosofía política de Hegel no podrá prescindir del contraste entre el texto editado por Hegel y el con-texto de las lecciones. Lo que él dice en las lecciones nos ayuda a explicar lo que él hace en el texto publicado.

\section{Los descubrimientos recientes}

3.1. Puede intuirse la extraordinaria importancia de los descubrimientos más recientes. La Nachschrift publicada por Henrich se refiere a la Rph III, es decir, a aquella lección que Hegel empezó el 25 de octubre de 1819, por tanto, inmediatamente después de la entrada en vigor de las «Deliberaciones de Karlsbad», y terminó el 18 de marzo de 1820. Si se tiene en cuenta que el prefacio a la obra publicada por Hegel es del 25 de junio de 1820, puede decirse que se trata del curso que invita, en mayor medida, a ser directamente contrastado con tal obra.

Para una información precisa sobre los orígenes de esta Nachschrift puede verse la cuidada «Bericht» a la edición de Henrich (págs. 297-311). Aquí se darán sólo algunas indicaciones. El volumen fue descubierto hace cerca de cuatro años en los Estados Unidos (en la Lilly Library de la Universidad de Indiana). Por desgracia el manuscrito no contiene indicación alguna sobre su autor o poseedor. Algunos añadidos en los márgenes del texto, con otra caligrafía y otra tinta, hacen suponer que el manuscrito tuvo por lo menos dos propietarios, antes de ser adquirido -junto a otros libros de carácter ius-político- por la Universidad de Indiana (mayo de 1896). El manuscrito publicado, que no procede (a diferencia de la Rph I y la Rph II) de un dictado hegeliano, probablemente no fue escrito durante las ho- 
ras de clase: de hecho, se trata de una bella copia compilada en base a apuntes. Resulta además evidente que la copia es de segunda mano por algunos errores que seguramente se deben a la transcripción: por ejemplo, la locución «fester Wille» (págs. 61 y 64) que aparece en lugar de «freyer Wille» se debe sólo a una confusión, por parte copista, entre «-y» y «-st». Lo mismo puede decirse del término «Bezeichnen» (pág. 75) que es transcrito como «Beziehen». Actualmente no puede establecerse cuál de los 54 auditores del curso de Hegel fue el autor de los apuntes de los que procede el manuscrito en cuestión, ya que si bien existe un índice general de los estudiantes de la Universidad de Berlín en el semestre de invierno de 1819-20, no hay una lista nominativa de los oyentes del curso de Hegel, Parece, sin embargo, que puede excluirse que se trate de Johannes Schulze, amigo de Hegel y asistente al curso. Sabemos, por alguna declaración suya relatada por C. Varrentrapp en Johannes Schulze und das preusiche Unterrichtswesen in seiner Zeit (1889, Leipzig, pág. 432), que Schulze asistió al curso y transcribió el texto de las lecciones, pero no puede inferirse de ello que el texto ahora publicado sea el suyo. D. Henrich (págs. 300-301), con razón, lo excluye principalmente por la comprensión defectuosa que demuestra el autor de la Nachschsrift en toda la primera parte y, en segundo lugar, por el hecho de que la biblioteca de Schulze fuera comprada en 1896 por la biblioteca de la Northwestern University de Evanston. Sólo se excluyeron de la venta aquellas obras de especial significado afectivo para la familia (cfr. K. M. Meyer: «Geschichte der Bibliothek des wirkl. geh. Oberregierungsrat D. Johannes Schulze», en Zentralblatt für das Bibl. Wesen, 42, 1925, págs. 615-620). Esta circunstancia explica además el hecho de que la Nachschrift sobre la Geschichte der Philosophie que se halla en la Northwestern University no proceda de la mano de Schulze. No es, por tanto, improbable que una Nachschrift suya de la Rph III esté escondida en alguna parte en Alemania.

3.2. La otra Nachschrift publicada por Ilting se refiere a Rph I, en es decir, al curso inmediatamente posterior a la publicación de la primera edición de la Enzyklopädie (junio 1817). Esta Nachschrift es, por tanto, la primera elaboración de la Filosofía del Derecho de Hegel y es, además, de especial interés para comprender el pensamiento ius-político de Hegel antes de su traslado a Prusia. En 1818 Heidelberg pertenecía a un estado -el gran ducado de Baden- y Berlín a otro -el reino de Prusia.

Las primeras noticias sobre este manuscrito se remontan a un artículo de J. Braun: «Hegel im Abfall und Gans in Heidel- 
berg», en Unireport, febrero de 1982, Manheim, págs. 8 y Sigs. ${ }^{14}$ Permítaseme resumir las aventuras de este ejemplar. En los años cincuenta un anticuario de Heidelberg, el señor Schäffner, comentó a un cliente suyo, el profesor de geografía Ernst Plewe, que se veía obligado a tirar un paquete de libros y manuscritos que no había conseguido vender. Plewe, rebuscando entre los papeles, descubrió la Nachschrift a la que nos referimos y el anticuario le regaló el manuscrito. Plewe, a su vez, se lo regaló al profesor de filosofía Fraz Joseph Brecht, en aquellos momentos Rector de la Universidad de Manheim. Brecht, contento por el regalo del manuscrito, lo colocó en su rica biblioteca personal, junto a otros de Heidegger y allí lo dejó hasta otoño de 1981 cuando el doctor Joachim W. Storck, del Deustsches Literatur-Archiv de Marbach, que había ido a consultar los manuscritos de Heidegger, descubrió el manuscrito de las lecciones de Hegel. El manuscrito está depositado en la actualidad en Marbach en el Deutsches Literatur-Archiv.

A diferencia de la Rph III, esta Nachschrift está formada por parágrafos seguramente dictados por Hegel y, por la profundidad de las Anmerkungen, hay buenas razones para considerar que éstas hayan sido transcritas muy fielmente. El autor es el estudiante P. Wannenmann, originario de Kreuznach (vid. G. Toepke/P. Hintzelmann: Die Matrikel der Universitdt Heidelberg, 5. Teil, 1904, Heidelberg, pág. 116). Puede ser de interés resaltar que Wannenmann siguió a Hegel a Berlín, donde, como aparece en su mismo manuscrito, transcribió el inicio de las lecciones siguientes (Rph II). En verano de 1820 -como se desprende de la fuente anteriormente citada- volvió de nuevo a Heidelberg. Entusiasmado por las lecciones de Hegel en Heidelberg le siguió a Berlín pero después, ¿quizás desilusionado?, abandonó la empresa.

\section{La estructura de Rph I en la Vorlesungsnachschrift de Wannenmann}

La estructura de Rph I permite hacer algunas consideracio-

${ }^{14} \mathrm{El}$ artículo con el título modificado y algún corte apareció posteriormente en el «Frankfurter Allgerneiner Zeitung», 30 de marzo, 1982, pág. 21; y con ulteriores variaciones en «Information-Philosophie», Heft 4, octubre 1982, con el título Hegels «ursprünliche» Rechtsphilosophie, págs. 7-13. Permítaseme, sobre este tema, remitir a mi nota «Del individuo y del Estado», en Revista de Estudios Políticos, núm. 44, marzo-abril 1985, págs. 125-135. 
nes previas. Sólo con una comparación superficial entre Rph I y HE $\S \S 400-452$ pueden verse diferencias significativas. En la Enzyklopädie de Heidelberg falta aún un desarrollo dialéctico entre, y dentro de, las partes: Derecho, Moralidad, Eticidad. Faltan además en este texto importantes elementos de la construcción sistemática de Rph I. La parte dedicada al derecho, por ejemplo, se articula ya en los momentos: persona-posesión y propiedad-contrato, pero está ausente un tratamiento de la sección sobre el «engaño». Es aún de mayor relevancia la ausencia total de la sección dedicada a la sociedad civil, que en Rph I adquiere ya la conformación que se reencontrará en el texto publicado. Ciertamente HE $\S$ 433 remite indirectamente al problema de la «bürgerliche Gesellschaft», pero la expresión no aparece y la referencia está inserta en un parágrafo en el que se habla de la familia. El tema aparece, sin embargo, en las anotaciones autógrafas de Hegel al mismo parágrafo, anotaciones que se remontan, como se ha dicho, al bienio 1818-19.

Además, la importante sección dedicada al derecho estatal interno se reduce en HE básicamente a los $\S \S 438-439$, mientras que en Rph I sigue la compleja articulación del texto publicado.

Nótese, sobre este aspecto, que la locución «Das innere Staaatsrecht» no aparece en HE y que en su lugar aparece la expresión «Das einzelne Volk». En HE el «pueblo» ocupa aún el lugar del «Estado».

Obsérvese, además, que la sección sobre el Estado de la Rph I presenta en su articulación conjunta una diferencia frente al texto publicado. En los tres cursos precedentes a la publicación de Rph la articulación es la siguiente: a) derecho estatal interno subdividido en: $\alpha$ ) poder del príncipe, $\beta$ ) poder del gobierno y $-\gamma$ ) poder legislativo; $b$ ) derecho estatal externo, y c) la historia universal. En la obra publicada, la articulación del punto a) se amplía dividiéndose en: I) constitución interna para sí, que comprende los tres poderes y II) soberanía externa. Precisamente en este segundo punto (II) se afronta específicamente el problema de la guerra y del estado de los militares que, en las lecciones, estaba comprendido dentro del derecho estatal externo.

Conviene además destacar que tampoco la separación entre poder del gobierno y poder del monarca, que aparece con toda su importancia en Rph I, se encuentra en HE, donde el príncipe es definido como «la culminación personal, deliberante y decisoria» del gobierno (HE § 438). Esta separación se halla en las anotaciones autógrafas de Hegel al parágrafo citado pero éstas son posteriores a Rph I. No aparece ninguna mención en 
HE $§ 439$ del debate constitucionalista de la época que constituirá el centro de la atención de Rph I. El ideal del pueblo ético, orientado según el modelo de la «polis» griega, prepondera aún en HE.

También la articulación de la sección dedicada a la historia universal (Rph I $\S \S$ 164-170) aparece apenas mencionada (falta, por ejemplo, la famosa cuatripartición de la historia universal) en los parágrafos (§§ 448-452) de HE.

Esta breve comparación permite llegar a algunas conclusiones relevantes: la estructura lógico-sistemática de la Filosofía del Derecho fue desarrollada por Hegel tras la publicación de la Enzyklopädie de Heidelberg, preparando su curso para el semestre invernal 1817-1818, es decir, en las vacaciones de verano (agosto-octubre 1818). Por tanto, a pesar de la cercanía en el tiempo entre HE y Rph I, en la construcción sistemática de ambas hay una apreciable distancia, mientras que, por el contrario, a pesar de que entre Rph I y la publicación de Rph transcurrieran tres años, existe una notable correspondencia en su estructura formal.

$\mathrm{Si}$, en relación a HE, Rph I presenta los cambios de estructura señalados, frente a Rph II aparece con una exposición mucho más detallada. Rph I supera sin duda a Rph II tanto por lo que se refiere al detallado y profundo texto de las Anmerkungen (se tiene casi la impresión de que pudieran haber sido dictadas por el propio Hegel) -frente al texto plagado de lagunas de la Rph II- como por la extensión del corpus de los parágrafos (170 frente a 142 de Rph II). Con Rph I nos encontramos frente a un texto que, por riqueza de contenido y profundidad de análisis, supera sin duda no sólo al fragmentario de Rph II, sino también al de Rph III, que, por el contrario, como veremos es mucho más discursivo.

En conjunto, Rph I aparece como la mejor fuente de conocimiento de la auténtica filosofía política de Hegel, antes de las sucesivas reelaboraciones. Precisamente este hecho es el que nos ha inducido a emprender la tarea de traducción que esperamos presentar al lector italiano en el plazo de tiempo más breve posible.

5. La estructura de Rph III en la Vorlesungsnachschrift anónima. Elementos para una comparación.

Teniendo en cuenta, sobre todo, la cercanía temporal, se tenían buenas razones para suponer que Rph III concordase am- 
pliamente con $\mathrm{Rph}^{15}$. Tal suposición, a la luz de la Nachschrift recién publicada, no parece confirmarse: ni por lo que se refiere al contenido, ni a la forma ${ }^{16}$.

Sobre el contenido, baste observar que Rph III no es menos liberal que las otras lecciones: en ella no se encuentran aún las huellas relevantes de la «Anpassung» a la política restauradora prusiana que caracterizan a la Filosofía del Derecho de 1820. Una comparación entre los distintos cursos (Rph I, II, III) sobre este aspecto muestra, aun cuando con diversas matizaciones, una convergencia sustancial.

En cuanto a la forma, sorprende que Hegel no dictase el corpus de los parágrafos (como había hecho anteriormente) y que hubiese renunciado a dividir la exposición (como en las lecciones precedentes, en la obra publicada y en las lecciones siguientes), presentando un texto homogéneo y compacto en el que incluso los pensamientos fundamentales, pertenecientes a los parágrafos, se exponen de forma muy libre a lo largo de la argumentación.

Este proceder relativamente libre se refleja también en la disposición y orden de las materias que difiere, en algunas partes de forma considerable, no sólo de Rph, sino también de los dos cursos de lecciones. Una comparación -que tomo, con alguna simplificación de Ilting $-{ }^{17}$ de los primeros cuatro parágrafos de la introducción de Rph con los lugares paralelos en los tres cursos de lecciones precedentes lo muestra con claridad:

$\begin{array}{llll}\text { Rph } & \text { Rph I } & \text { Rph II } & \text { Rph III } \\ \S 1 & \S 1 & \S 1 & 52,14 \\ \S 2 & \S 3 & \S 4 * \mathrm{a} & 56,23 \\ \S 3 & \S 1 \mathrm{~A} & \S 2 & 53,3-54,8 \\ \S 4 & \S 2 & \S 3 & 52,15-23\end{array}$

(*a indica la primera parte del párrafo)

Entre Rph I y Rph II la diferencia es sólo de numeración:

${ }^{15}$ Cfr. K.-H. Ilting, Hegel diverso, op. cit., pág. 127. Además el Vorwort a Hegel, Vorlesungen über Rechtsphilosophie, op. cit., Bd. II, págs. 7 y sigs.

${ }^{16}$ Como ya ha reconocido Ilting en su trabajo más reciente: «Zur Genese der Hegelschen ?Rechtsphilosophie”», en Philosophische Rundschau, 1983, Heft 3-4, págs. 163-165 y pág. 174.

${ }^{17}$ Vid. págs. 165-167. 


$\begin{array}{ll}\text { Rph I } & \text { Rph II } \\ \S 1 & \S 1 \\ \S 1 \mathrm{~A} & \S 2 \\ \S 2 & \S 3 \\ \S 3 & \S 4 \mathrm{a}\end{array}$

el procedimiento de la argumentación es ampliamente concordante. A una definición del Derecho natural $(\S 1=\S 1)$ sigue la determinación del derecho positivo $(\S 1 \mathrm{~A}=\S 2)$ y la consideración de la filosofía del derecho como parte del sistema filosófico $(\S 3=\S 4 \mathrm{a})$. Esta construcción, en sí muy clara y convincente, aparece muy cambiada en Rph. Considerando sólo los aspectos formales de este cambio y teniendo en cuenta la tabla introducida, en Rph Hegel empieza con la identificación del objeto de la filosofía del derecho ( $\$ 1$ que a decir verdad no concuerda del todo con Rph I §1 y Rph II §1, ya que no habla de derecho natural), continúa con la observación de que la filosofía del derecho es parte del sistema (Rph $\$ 2=$ Rph I $33=\mathrm{Rph}$ II $\S 4 \mathrm{a})$, sigue deteniéndose en las diferencias entre derecho natural y derecho positivo (Rph $\S 3=\mathrm{Rph}$ I $\S 1 \mathrm{~A}=\mathrm{Rph}$ II $\S 2$ ) y concluye con la idea de la libertad como principio del derecho (Rph $\S 4=\mathrm{Rph}$ I $\S 2=\mathrm{Rph}$ II $\S 3$ ). Si nos fijamos sólo en los aspectos formales del cambio habrá que concluir que éstos se reducen a una diversa concatenación y a un diferente desarrollo de los mismos temas. La diferencia más relevante es que aquello que constituía el $\S 4$ en Rph II (y $\S 3$ en Rph I) se adelanta y pasa a ser el $\S 2$ en Rph. Desde el punto de vista formal, del armazón, puede por tanto constatarse una notable correspondencia entre Rph I, Rph II y Rph.

La forma de proceder en Rph III es, al contrario, muy divergente. Comparando Rph III con Rph podrá observarse un cambio casi total:

$\begin{array}{ll}\text { Rph III } & \text { Rph } \\ 52,14 & \S 1 \\ 52,15-23 & \S 4 \\ 52,24-53,2 & \S 30 \\ 53,3-54,8 & \S 3 \\ 54,9-56,22 & \S 33 \\ 56,23-58,21 & \S 2\end{array}$

En primer lugar Hegel identifica el objeto del tratado $(52,14)$ 
sin que el autor de la Nachschrift aporte precisión alguna sobre este punto; a continuación $(52,15-23)$ aparece la identificación del derecho con la libertad que se realiza; prosigue con observaciones sobre la forma de proceder del tratado $(52,24-53,2)$ y con observaciones que se refieren, si bien indirectamente, a la relación entre derecho natural y derecho positivo (53, $3-54,8)$; y sigue la partición $(54,9-56,22)$ y la consideración de la ciencia del derecho como parte de la filosofía $(56,23-58,21)$. Puede, por tanto, concluirse que existe mayor correspondencia entre Rph I, II y Rph que entre Rph III y Rph, a pesar de que aparentemente podría pensarse lo contrario.

$\mathrm{Si}$, en base a los cotejos efectuados, se ha aclarado la peculiar posición de Rph III, parece difícil sostener que Hegel leyera sus lecciones sobre la base de un (hipotético) manuscrito $^{18}$. Las amplias libertades que Hegel se toma en la exposición y el carácter extremadamente discursivo de las argumentaciones, documentado, entre otros, por la falta de la habitual distinción entre parágrafos y anotaciones tienden a hacer pensar que Rph III fuera leída siguiendo apuntes («Notizien»). En una mirada superficial puede parecer insignificante el hecho de que Hegel no hubiera dictado Rph III y, en consecuencia, puede parecer desproporcionada la atención que le hemos dedicado. Pero precisamente este simple hecho es el indicio que permite obtener una importante confirmación: Hegel creía poder disponer ya al inicio de Rph III, o por lo menos durante el semestre de invierno 1819-20, de su texto impreso y, en consecuencia, podía parecer superfluo e incluso desaconsejable, teniendo en cuenta la incierta situación política ${ }^{19}$, el dictarlo.

Si ello es cierto, queda confirmada expresamente la hipótesis, adelantada por Ilting hace ya diez años, de la existencia de un manuscrito (perdido) de Rph que debía ser impreso cuando acontecieron las deliberaciones de $\operatorname{Karlsbad}^{20}$.

${ }^{18}$ De esta opinión, por el contrario, parece ser Henrich en el Bericht a su edición (op. cit., pág. 309). Contra Ilting, vid. pág. 165 y pág. 172.

${ }^{19}$ Es cuanto añade con razón Henrich (op. cit., pág. 306).

${ }^{20}$ K.-H. Ilting, Hegel diverso, op. cit., págs. 75 y sigs. Esta tesis había sido discutida por Horstmann en «Ist Hegels Rechtsphilosophie das Produkt der politischen Anpassung eines Liberalen?», en Hegel-Studien, Bd. 9, 1974, págs. 241-252 (246-248). Concuerda con Ilting, si bien con algún matiz, Henrich (op. cit., pág. 308). Desarrollo de este argumento en mi nuevo libro: Le filosofie del diritio di Hegel, Milán, F. Angeli, 1990. 


\section{Variaciones sobre un antiguo tema}

Como conclusión a este artículo querría centrar brevemente la atención en las variaciones que se producen, desde el punto de vista de su contenido, entre el texto impreso y los cuadernos de las lecciones. En otra ocasión me he ocupado de las diferencias existentes referidas al poder del príncipe ${ }^{21}$, aquí quiero desarrollar alguna observación relacionada con el famoso dicho: «Lo que es racional es real; y lo que es real es racional» (Rph, pág. 70, 28-29). El contexto en el que se inserta este dicho, en el Prólogo, tras la dura invectiva contra Fries, no deja dudas acerca de su significado político: la filosofía política de Hegel, en plena Restauración, enseña a «mantenerse en paz con la realidad» (Rph pág. 74, 5-6) atacando a todos aquellos que por el contrario han llegado a una «abierta ruptura» con ella. La «reconciliación con la realidad» (Rph, pág. 73,7$)$ se pagaba al caro precio de declarar racional la realidad existente. Como es sabido, Hegel en la segunda edición de la Enziklopädie (1827), aborda el intento de defender su afirmación de los múltiples ataques, distinguiendo entre realidad («Wirklichkeit») y existencia («Dasein»/ «Existeriz») 22 . Pero Hegel no puede demostrar haber tenido en cuenta tal distinción en la Filosofía del derecho. Aquel dicho, en el contexto en que se insertaba, no podía sino expresar una justificación ideológica de lo existente, una adaptación política a la realidad histórica presente.

No se encuentra en cambio señal alguna de tal actitud en los pasos correspondientes de los tres cursos precedentes:

\section{Rph I}

Lo que es racional debe («mu $\beta »)$ suceder.

(Rph 1, § 134 A, pág. 157, (Rph II, página 232, 27). 4).

Rph II Sólo lo racional puede suceder.
Rph III Lo que es racional deviene real, y lo real deviene racional. (Rph III, página 51, 4-5).

En Rph I Hegel acentúa sobre todo la necesidad de un desarrollo histórico de lo racional dentro de un espíritu del pueblo

${ }^{21} \mathrm{P}$. Becchi, «El simulacro de la decisión. Diferencias en la doctrina hegeliana del poder del príncipe», en Revista de Estudios Políticos, núm. 49, enero-febrero, 1986, págs. 63-86.

${ }^{22}$ G. W. F. Hegel, Sämtliche Werke, cit., vol. 8, § 6A, pág. 48. 
(el fundamento de la realización histórica de lo racional se ve aquí en el desarrollo del espíritu del pueblo). Rph II subraya esta necesidad hasta el punto de negar que «fenómenos externos singulares», que parecen oponerse a la realización de lo racional, puedan obstaculizar de forma decisiva su desarrollo. Rph III repite esta convicción recalcando que la realización de lo racional es un proceso que encuentra su perfeccionamiento en el futuro. Ciertamente los acentos que Hegel pone en estas formulaciones son diversos, pero permanece invariable el «leit motiv» de una discrepancia entre razón y realidad. Y es precisamente esta discrepancia la que desaparece en la formulación de 1820. Como quiera que se interprete, la identificación de razón y realidad sustraía a la filosofía política el terreno para una confrontación crítica con la realidad histórica, sirviendo primorosamente a una consagración (filosófica) de las relaciones existentes.

El simple cambio de la forma verbal («müssen», «können», «werden» contrapuestos homogéneamente al «sein») es el indicio de otra transformación significativa, referida a las tareas y el papel de la filosofía del Derecho. En el Prólogo de 1820 la filosofía del derecho «no puede llegar a enseñar al Estado como debe ser, sino más bien [debe mostrar] en qué forma éste, el universo ético, deba ser reconocido» (Rph, pág. 72, 10-13). Las tareas de la filosofía del derecho se reducen a la «comprensión de lo presente y de lo real» (Rph, pág. 70, 7-8), ya que «como pensamiento del mundo, ésta aparece por primera vez en el tiempo, después de que la realidad haya cumplido su proceso de formación y esté realizada» (Rph, pág. 74, 9-13). Decididamente contraria es la actitud de Hegel en Rph II en la que la ciencia filosófica del derecho tiene por objeto «el alto concepto de la naturaleza de la libertad, sin relación con lo que está en vigor, [sin relación] con la representación del tiempo» (Rph II, pág. 234, 3-5). Aquí Hegel se opone de forma inequívoca incluso a aquella reducción, en mera comprensión de lo presente y lo real, realizada en el Prólogo de 1820. Tanto contra el justificacionismo historicista de Savigny cuanto contra el extremismo subjetivista de Fries, Hegel alcanza a presentar su filosofía del derecho más bien como la auténtica aliada del «actual espíritu del tiempo» (Rph II, pág. 232, 16-18 y 30). Su filosofía del derecho no queda fijada ni en la abstracción (Fries), ni en la consideración histórica (Savigny): «Sabe que el reino del derecho sólo puede nacer mediante un desarrollo progresivo y que no es posible saltarse ninguna de sus fases... por ello, cuando el espíritu del pueblo llega a una fase superior, los momentos de la constitución necesariamente y ninguna fuerza puede mantenerlos») (Rph II, 
pág. 232, 18-62). No debía ser sustancialmente diversa la posición de Hegel en el Prólogo (que como se ha dicho no se conserva) a su primer curso de filosofía del derecho, ya que en las anotaciones a un importante parágrafo nos presenta su filosofía como aliada de un gobierno capaz de mediar entre las reivindicaciones del pueblo y las instancias del monarca para un «abandono de la vieja involución y un rejuvenecimiento de la constitución» (Rph I, $\S 134$ A, pág. 156, 50-51).

A pesar de que en Rph III la incidencia activa de la filosofía en el tiempo histórico ya esté atenuada, aún parece de forma clara en este curso que la filosofía no se contenta con la contemplación de lo real: «así vemos que se presenta en Platón, Sócrates, Aristóteles, en el tiempo en que la vida griega se aproximaba al ocaso y el espíritu del mundo llegaba a una más alta consciencia de sí mismo» (Rph III, pág. 51, 19-22). Aquí es precisamente la filosofía la que se halla en un punto de transición: sella el ocaso de una época y prepara el terreno para el novum histórico. Este pensamiento se extiende también a la época romana y medieval: «de forma más débil esto se repitió también en Roma cuando cesó la peculiar vida romana y asumió otra forma. Descartes apareció porque el medievo había llegado a su fin» (Rph III, pág. 51, 22-25). Recuérdese que la interpretación de Platón aparece también en el Prólogo al texto de Hegel publicado (Rph pág. 70). No puede dejar de ponerse de relieve que esta explicación está en flagrante contradicción con todo el contexto en el que se inserta. ¿Cómo puede conciliarse la afirmación de que la grandeza de Platón reside en haber anticipado «el inminente trastorno del mundo» con la afirmación expresada en la misma página de que la filosofía se debe limitar a la «comprensión de lo presente y lo real»? Y ¿»en qué relación está la interpretación de Platón con la identidad de lo racional y lo real que de forma totalmente injustificada le sigue? ¿No es esto sino una confirmación ulterior de la reelaboración efectuada por Hegel? Hegel ha dejado la referencia a Platón pero la ha insertado en un contexto que la hace totalmente incomprensible. Creo que ha aparecido con suficiente claridad que la filosofía del derecho en los tres cursos que preceden a la publicación de las Grundlinien no se reduce a mera comprensión del presente, a justificación ideológica de lo existente. En el alba del espíritu aún no hay lugar para la lechuza de Minerva. 


\section{SIGLAS Y ABREVIATURAS}

[ ] Añadidos del autor.

A Indica que se refiere a las anotaciones (Anmerkung) del párrafo citado.

Briefe I / IV Briefe von und an Hegel, herausgegeben von J. Hoffmeister, 4 Bde, Hamburg, Meiner, 1952, 1953, 1954, 1960. Citadas por la tercera edición (1977) reelaborada y ampliada por F. Nicolin.

HE Encyklopädie der philosophischen Wissenschaften im Grundrisse, Heidelberg, 1817, que, en relación a la sección dedicada al espíritu objetivo, se cita por la edición Ilting, reproducida en G. W. F. Hegel, Vorlesungen über Rechtsphilosophie, Stuagart-Bad Cannstatt, Fromann-Holzboog, 1973-1974, vol. I.

Rph Grundlinien der Philosophie des Rechts, Berlín, 1821. Citado por la edición Ilting, reproducida en las Vorlesungen über Rechtsphilosophie, vol. II

Rph I Vorlesungen über Rechtsphilosophie 1817-18. Citada por la edición Ilting, publicada en G. W. F. Hegel, Die Philosophie des Rechts, Die Mitschriften Wannenmann (Heldelberg, 1817-18) und Homeyer (Berlin 1818-19), Stuttgart, Klett-Cotta, 1983.

Rph II Vorlesungen über Rechtsphilosophie 1818-19. Citada por la edición Ilting; Vorlesungen über Rechtsphilosophie, vol. I.

Rph III Vorlesungen über Rechtsphilosophie 1819-20. Citado por la edición Henrich: Philosophie des Rechts, Frankfurt a. M., Suhrkamp, 1983. Los números de Rph III se refieren a las páginas y a las líneas.

Rph IV Vorlesungen über Rechtsphilosophie 1821-22.

$\mathrm{Rph} \mathrm{V}$ Vorlesungen über Rechisphilosophie 1822-23. Citada por la edición Ilting: Vorlesungen über Rechtsphilosophie, vol. III.

Rph VI/ Rph VII Vorlesungen über Rechtsphilosophie 1824-25. y 1831. Citadas por la edición Ilting: Vorlesungen über Rechtsphilosophie, vol. IV.

\section{DOXA-8 (1990)}

